\title{
Social Mobility of Migrant Peasant Workers in China
}

\author{
Ke-Qing Han $^{1}$, Chien-Chung Huang ${ }^{2}$, Wen-Jui Han $^{3}$ \\ ${ }^{1}$ Renmin University of China, Beijing, China; \\ ${ }^{2}$ Rutgers University, New Jersey, USA; \\ ${ }^{3}$ New York University, New York, USA. \\ Email: kq_han@ruc.edu.cn \\ Received July 2 ${ }^{\text {nd }}$, 2011; revised August $15^{\text {th }}$, 2011; accepted September $18^{\text {th }}, 2011$.
}

\begin{abstract}
Using data from four cities in China (Shenzhen, Suzhou, Beijing, and Chengdu), this article examines the occupational and social mobility among migrant peasant workers in urban areas. Through qualitative interviews with 109 peasant workers in 2005, we found that institutionalized social structures, such as the household-registration system, constrain the occupational and social mobility of rural peasant workers who migrate to and reside in urban areas. Obtaining more education and skills appear to be viable mechanisms for at least some migrant peasant workers to achieve higher occupational or social status in the city. Nonetheless, after several years of working in the urban areas, many rural workers plan to return to their rural hometowns, largely due to the social exclusion they experienced in the cities.
\end{abstract}

Keywords: Migration, Occupation Mobility, Peasant Workers, Social Mobility, Status Attainment

\section{Introduction}

China has undergone great changes in social structure and class hierarchy since the economic reform of 1978, which moved the country from a planned economy to a market economy (Chan \& Zhang, 1999; Bai \& Li, 2008; Lin, 2009). Since then, the two-tiered class system consisting of laborers (nonagricultural, usually urban workers) and peasants (agricultural workers) that had served as the basic unit of China's social structure has gradually disintegrated (Bian, 2002; Wu \& Treiman, 2004, 2007). For example, Bian (2002) examined social stratification and social mobility in China and found that the economic reforms and ensuing rise of the market economy since 1980 disintegrates many traditional divisions in Chinese society, including the demarcations between urban and rural areas, work-unit boundaries, the dichotomous classification of party leaders and workers, and political barriers to the institutionalization.

Despite these substantial changes, the stringent household registration system (hukou) that was set up in 1955 still creates notable divisions between the urban and rural populations. In this system, everyone is assigned either an agricultural (rural) or nonagricultural (urban) hukou at birth on the basis of the mother's registration status, and residents must be registered in the locale where they resided (see Chan \& Zhang, 1999, for a historic review of the household-registration system in China). The rural agricultural households are traditionally confined to the countryside and entitled to very few of the social benefits offered to residents born into urban areas by the government, such as medical insurance, housing subsidies, pensions, and educational opportunities for children. Before the 1978 economic reform, migration between rural and urban regions was prohibited. In the early 1980s there was a growing demand for the labor market to become more compatible with the market economy. In 1984 the government relaxed the traditional hukou migration restrictions and allowed peasants to move into the city, thus opening the door to large-scale rural-to-urban migration. This policy change, coupled with rural land reform and speedy urban industrialization, large numbers of rural laborers migrated into the urban areas (Chan \& Zhang, 1999; Bian, 2002; Zheng, 2006). This labor force is called migrant peasant workers because they are registered as farmers or peasants in the household-registration system but they migrate and engage in nonagricultural industrial labor. Migrant peasant workers, however, are not eligible for high-level positions within the government in urban areas unless they have permanent urban registration status. This is the case even if the migrant peasant worker was born in a city but his or her mother holds a rural household registration. The household-registration system still serves as an important mechanism in distributing resources and determining life chances in China today (Chan \& Zhang, 1999; Wu \& Treiman 2004).

The number of migrant peasant workers has increased substantially over the past two decades and have become a huge part of the urban labor force. Before 1990, the number of migrant peasant workers was estimated at about 25 million. This number increased substantially after 1990 and was estimated to be 94 million in 1995 and 200 million in 2004 (State Council Research Office, 2006; Li \& Li, 2007). The number in 2004 represented $40 \%$ of the rural labor force. In 2004, the average age of migrant peasant workers was 28 , the majority had a junior-high-school education, and they mainly worked in the manufacturing, construction, and service industries (State Council Research Office, 2006).

The large-scale migration of peasant workers has become an important social phenomenon with great implications for their geographic, occupational, and class mobility. In particular, peasant workers cross geographical boundaries and into more developed regions, work in new industries, and earn higher incomes. Research has shown that the first change experienced by migrant peasant workers usually involves upward occupational mobility, changing from being an agricultural worker to an industrial laborer (Li, 2004). After this initial upward move from the rural to urban labor force, most migrant peasant workers are unable to move up to higher positions in urban industries, even when changing between jobs (Li, 2004). Migrant peasant workers tend to earn lower wages than native-born urban residents and frequently change jobs in an often futile 
effort to better their situation. In short, despite the institutionalization of rural-to-urban migration (Chan \& Zhang, 1999; Wu \& Treiman, 2004; Li \& Li, 2007), migrant peasant workers experience numerous social disadvantages in urban areas and continue to be a marginalized group in Chinese society.

\section{Theoretical Framework: Social Stratification and Mobility}

Classical social-stratification theory states that an individual's position in society is determined by a number of dimensions such as class, status, and power (Weber, 1964; Lenski, 1984; Levine, 2006; Watson, 2010). Class refers to a person's economic position and status is a person's prestige or social honor in society. Power is a person's ability to carry out his or her will despite the resistance of others. Status essentially determines an individual's social network. Max Weber described status groups as tending to draw a circle around themselves to bound their social interactions, marriage, and other relationships. The status group, thus, develops into a closed social class (Weber, 1964; Kerbo, 1991; Levine, 2006). A person's power can be shown in the economic order through their class, in the social order through their status, and in the political order through their party. This multidimensional approach of social stratification theory reflects the interplay among wealth, prestige, and power in society (Weber, 1964; Lenski, 1984; Levine, 2006).

\section{Method}

Using case interviews of 109 migrant peasant workers from 2005, this article qualitatively explores the status attainment and contributing factors to social mobility among migrant peasant workers in four cities (Shenzhen, Suzhou, Chengdu and Beijing) in China between July and November of 2005. The data came from the Social Protection of Migrant Peasant Workers in China Survey. Using a convenient sampling strategy, the survey collected data in main train stations of the four cities. The survey was administered by professors from the Renmin University of China and Hong Kong City University.

Narrative interviews were first transcribed word by word. We read through each of the transcripts with the aim of finding common as well as divergent themes. The authors analyzed all 109 interviews, and identified three major themes that were common among most surveys: the status attainment of migrant peasant workers, upward mobility, and returning home. For this paper we selected surveys that represented these major themes. We also collectively identified several survey responses that diverged considerably from the major themes, and we present excerpts from those to demonstrate the sample's diversity.

\section{Results}

\section{Status Attainment of Migrant Peasant Workers}

As discussed above, the household-registration system is a unique phenomenon in China. This registration system essentially structures China's society into urban and rural areas, with urban and rural residents living in two different worlds and forming two differential ways of life since 1955. Although China's entry into the market economy has loosened the geographical restrictions of the household-registration system, other infrastructure arrangements that are attached to household registration, such as the social-welfare system, have not been reformed. Urban citizens and peasants in China's society are two different social classes. Although peasant workers live and work in urban areas together with urban residents, clear social-class distinctions are apparent and have great implications for the social exclusion experienced by migrant peasant workers. This social exclusion has effectively prevented migrant peasant workers from attaining urban status, which is considered to be higher than rural status in China's household-registration system. A 30-year-old unmarried male peasant worker with an elementary school education who moved to Chengdu in 1995 illustrates what his daily experiences were like living in the city:

Q: Do you feel that urban citizens treat you equally?

A: Urban citizens see you as a peasant worker and as a farmer. You are not on the same level as they are. A peasant worker is always a peasant worker, and a farmer is a farmer forever. Your social status is one level lower than theirs; actually, it is lower than the lowest level.

Q: Do the supervisors and coworkers in your organization or company all see you like this?

A: Oh, yeah.

Another migrant peasant worker, a 34-year-old married female with a high-school education who first moved into the city in 1992, now works at a barber shop.

$\mathrm{Q}$ : Do you think rural people and city people are equal?

A: Equal? Ah. Urban people think you are a farmer; that shows the discrimination right there. One of my husband's neighbors been found out that he did not have a temporary residence permit and someone called the authorities. He had been sent away in 1999. No one knows if he is alive or dead.

The two cases above illustrate that geographical boundaries associated with the household-registration system determine which social group an individual belongs to, and regional identity is a deep-rooted cultural reality in Chinese society. In the course of migration to urban areas, peasant workers face social exclusion that results from geographic differences (rural villages versus cities) and from not being allowed to obtain an urban household-registration status.

A 42-year-old married male migrant peasant worker with a high-school degree who first moved to the city in 1997 works as an industrial manager. One of his interview responses illustrates the extent to which geographic boundaries and the household-registration system divide social groups, as well as how languages are part of an individual's identify and define social groups.

Q: You have moved between many places, such as Guangdong and Suzhou. Could you say more about the time you spent with the residents who were native to those urban areas?

A: My feeling is, the Cantonese [urban residents in Guangdong] have an exclusive psychology. Why do I say they have xenophobia? Because many companies give priority to people who can speak Cantonese when recruiting workers, some even just hire workers who can only speak Cantonese. The language preference excludes a lot of peasant workers. I think that is a form of discrimination in Guangdong. It is true that the whole country is being pushed to learn Mandarin, but the Cantonese do not want to learn Mandarin; and actually, they want people to adapt to their language and their local culture.

Another 30-year-old married male peasant worker with a junior-high-school education who is a veteran and first moved to Shanghai in 1998 discusses social exclusion as well. 
Q: Have you been to Shanghai?

A: Been there, just once-very exclusive. I was trying to make a phone call back to my home. I did not have a phone so I found a phone on the street. It looked like it was a public telephone that could only make local calls. But I didn't know. I asked people who were passing by the phone booth how to make a call. They did not even bother to answer me-just gave me a look. Or, even if they answered, I mean, you could kindly tell me that this phone is for local calls, but their tone was really mean and discriminatory, very exclusive.

The above two cases illustrate how the social exclusion of migrant peasant workers in China is a continuation of the long-standing urban-rural household-registration system and the resulting geographical exclusion. Through our interviews, we found that migrant workers respond strongly to exclusion in various dimensions of social life and cultural identity.

\section{Upward Mobility of Migrant Peasant Workers}

It is true that most migrant peasants work at low-skilled, low-paying jobs that urban workers do not want. Additionally, most migrant peasant workers do not experience upward occupational mobility as time goes by and as they change jobs over the years. Still, it is equally true that some migrant peasant workers make their way up the occupational ladder to obtain high socioeconomic status after years of hard work. A 29-yearold male with a high-school degree who moved to the city for the first time in 1997 used his own experience to vividly explain how upward mobility is possible even for peasant workers.

Q: Could you tell us about your promotion process since you first moved to the city 8 years ago?

A: I started as a cleaning worker in a Japanese-run company for 3 months. After that, I was transferred to the mold manufacturing sector, and was responsible for the maintenance of six sets of tools. This job was recruited for internally but required that [the applicant] take and pass the company's written examination. I did not know about the test, so I did not apply. On the day of the examination, I saw many young men take their pens with them for the examination. I felt that my opportunity was coming, so I put down my work at hand, and followed the people to take the examination. My score was ranked as the second best, but the requirement for the written examination was to have the top score. My supervisor had a very good impression of me, so he gave me very high evaluation, and I was selected for the job because of the examination and the evaluation.

Q: What happened after that?

A: The new job was very much like the one I had before. Two men worked at this job before me, they both worked for 2 years and they were still technicians without any promotion, so they quit. I took on both of their responsibilities, so the workload was double. The temperature of the workshop was higher than 40 degrees $\left(40^{\circ} \mathrm{C}=104^{\circ} \mathrm{F}\right)$, I was all sweaty when I did the work every day. I was very tired. Despite the hardship, I learned about loading and unloading the materials while I maintained the equipment, I also learned to drive a forklift, and got a license for that. I worked very hard and got recognition from my supervisor. He told the Japanese boss about my performance. I was promoted to team leader a few months later. I took on the team-leader position for one year.
Q: What was the biggest gain after you were promoted to team leader?

A: One of the biggest gains was the increase in salary, but the responsibility increased as well. Also, I had more opportunities to interact with my colleagues and superiors, and thus more colleagues knew me and knew about my strengths and weaknesses as well.

Q: You then changed positions again?

A: Yes, from 1999 to 2001, I was transferred to and worked for a department that was responsible for ordering foreign products, for expediting product deliveries, and also for team communication and quality inspection.

Q: At that time your job had changed from a laborer to a manager, were you satisfied?

A: I felt very satisfied, but in my mind I still wanted to climb higher (beaming smile).

Q: You succeeded, right?

A: Yes, on November 1, 2001, I joined the company's Headquarter Office, responsible for managing six depart ments.

Q: You said so yourself: you don't have a lot of education. So, what are the reasons for your success?

A: I came from a rural area and did not have good education or skills. The decor skill I learned was neither my specialty nor my interest. I made my mind up in the beginning that I have to learn new skills, to revitalize myself, and keep climbing up.

Q: What kind of things you have done to advance yourself? Why did you challenge yourselves to learn new things constantly?

A: I now study safety management in engineering in college. I will get the diploma in 2 years. I would like to move higher, and this would be impossible if you do not have a college education. With more and more college graduates now, competition has been growing as well. Workers are increasingly aware of work-related injuries, and companies need professionals to control and manage the risks. I can get a better job if I earn my diploma. These classes are on weekends. I go to work on weekdays and go to school on weekends. Sometimes, I feel tired and exhausted, but I always am trying to keep working towards success. Two years is not a long time!

Q: We are toward the end of our interview what else would you like to say?

A: I want to say that you must stick with your education, be confident, and trust your own ability. Learning is an investment in your future. The disadvantage of migrant peasant workers is caused by their family background, and they must rely on their own effort to make up for it. Migrant peasant workers are like the city people. We are all the same. We are all human beings, just born with different backgrounds. Sometimes, in the city, people do not discriminate against you, but you did not take the opportunity. A boy went to the factory with me in 1997. He worked for 5 years, still at the lowest level, and finally left. The reason was that he did not work hard enough and did not have a strong sense of responsibility. So I think, migrant peasant workers in the cities need to believe in themselves, need to work harder than others. If so, they must be able to succeed.

This interviewee obviously has a proactive, hardworking, and responsible personality. He experienced a great deal of struggles in the beginning of his career, but all he could think of was to learn new skills and work hard. As he understands and 
exemplifies, the purpose of learning skills is to continue moving up. He was promoted to the management position, and was still thinking of climbing the ladder. Through his continuous learning, he was gradually promoted to personnel director. His experiences may be unique, but his path to success is shared by many peasant workers. As he said, the disadvantages of migrant peasant workers stem from their family background-the household-registration system in this case-and that is it. To move upward and to be freed from the constraints of the household-registration system requires individual effort to advance one's education and job skills.

Modernization theory argues that a traditional society usually constitutes a rigid structure to confine people's behaviors and thus their status; the social mobility of individuals is severely restricted (Kerbo, 1991). A modern society is an open society without a rigid structure, and thus social mobility between strata is not restricted. In a traditional society, the social status of individuals was depended mainly on inheritance. In contrast, people rely on education and skills to achieve high social status in a modern society. Through the interviews, we found that although China's household-registration system presents itself as a traditional society, the open economic market since 1987 has allowed migrant peasant workers to obtain better employment opportunities and thus a greater degree of upward mobility through education and skills training.

\section{Going Back Home}

Since the early 2000s, the number of migrant peasants who work in urban areas is growing at a fast pace. The influx of new peasant workers migrating to the cities every year is growing. But this does not mean that no peasant workers are leaving the cities. Indeed, the recent few years have seen a steady number of migrating peasant workers moving back home in the rural regions. Many reasons account for why peasant workers may return home. Bai and $\mathrm{He}$ (2003) examined the contributing factors to remigration and found that the primary reason was the difficulty obtaining employment in the urban areas. Some peasant workers returned to rural areas because of personal and family reasons, and others wanted to return to their hometowns for the purpose of investment. In our case interviews, many migrant peasant workers reported that they did not want to stay in the city their whole life and planned to work for a few more years and then return to their hometown to farm or to own their own business. Our conversation with a 20 -year-old male with a junior-high-school education who moved to the city in 2001 provides one such example.

Q: If possible, will you stay in the city forever?

A: I don't want to.

Q: Why?

A: Because it is not ideal in the city. If you are unemployed in the city, there is no way to get by. In the rural area back home, at least you have land-you can plant something to eat.

A: 38-year-old male who first migrated to the city in 1988 and who was a fruit-and-vegetable vendor gave a different reason:

Q: Are you planning to stay in the city for the long term?

A: We have a saying in our hometown: a tree may be one thousand feet above ground, but the leaves still trace back to the roots. I will work for another 10 years or so, then go back. The city, after all, is not my home.

Q: You have never thought about listing your household in the city?

A: No. I may be able to register my household in the city if I try, but I never did. The urban household registration does not have much use for me now. My kids are all out of school, and if I list my household here, they will take my rural land away.

In the above cases, both the first-time migrant peasant worker and the experienced peasant worker expressed that returning to their hometown was a future plan. These cases certainly raise the question that if migrating to the city is done to achieve upward social mobility, then why would some or many peasant workers want to go home in the end? In our interviews with the peasant workers, we find that going back home was somewhat of a powerless choice. Although peasant workers may consider moving from the rural to the urban area and from agriculture to industrial employment as upward mobility, living and working in the city seems to bring with it a reality check of social exclusion and infrastructure barriers that seriously limit their social status. Although peasant workers may take the first step on the ladder of potential upward mobility by obtaining industrial work in the city, they face many difficulties in blending into the city life. In the end, returning home may be a better option for migrant peasant workers who wish to improve their social status.

\section{Discussion and Conclusion}

The literature has argued that the social mobility of migrant peasant workers is an advancement in the process of social development in China, has a positive influence on the urbanization process, and makes substantial contributions to the growth and transformation of the country's economic system (Bai \& He, 2003; Zheng, 2006; Li \& Li, 2007). For example, the State Council Research Office (2006) of the Chinese national government estimates that, in 2004, migrant peasant workers have contributed 1 to 2 trillion yuan to the GDP with their urban work activity and increased rural revenue by 500 to 600 billion yuan. It is estimated that over $20 \%$ of the increase in the GDP from 1978 to 1995 was attributable to migrant peasant workers; this percentage is higher than that of improved institutional factors, such as the shift from low-productivity sectors (agriculture) to high-productivity sectors (nonagricultural; Cai \& Wang, 2002 and 2010).

The phenomenon of migrant peasant workers, however, highlights the contradiction of social structures in traditional agricultural society and the modern industrial system. In our qualitative study, we illustrate the difficulty experienced by many peasant workers living in the city, including discrimination and social exclusion, and how such experiences have limited their status attainment in the city. We also show that there are at least two directions taken by peasant workers in their career paths. One is clearly to achieve upward occupational mobility, and the other is to return home to farm. It seems that many peasant workers choose to go back home to avoid giving up the land that was passed down to them through the generations. Behind their words, they expressed concern that a job can be very helpful for the time being, especially if it brings good money and supports a decent living standard for the worker and his or her family, but land is a permanent asset that is valuable and can be passed onto many future generations. Although peasant workers may choose to register their household in the city to obtain a "higher" social status for their children and future generations (a benefit that many peasant workers would like to enjoy), having an urban household registration also requires giving up land, which may result in a greater loss than the worker can gain by switching household registrations. 
The qualitative findings from this study highlight a common experience shared among migrant peasant workers: discrimination and social exclusion. Still, with diverse career paths, some of the migrant peasant workers achieved upward occupational mobility and others went back home to return to their old work in farming. These findings emphasize the importance of future research to understand the heterogeneous experiences and mobility paths among peasant workers. Although many people, including the peasant workers themselves, consider migrating for work to be upward occupational mobility, we cannot overlook the possibility that returning home can be a positive choice for many migrants. Perhaps what this study highlights is that no one experience should be considered better than others.

We conducted this study to attempt to better understand the experiences of peasant workers from their own words and perspectives. What we learned from their interview responses was that to promote the well-being of peasant workers and to improve their social status and chances for upward mobility requires active policy intervention. The findings of this study may offer several implications for policy and future research directions. The first has to do with the institutionalization of social mobility for migrant peasant workers. The migration of peasant workers historically began with a spontaneous flow initiated by individual peasant workers crossing illegally into urban areas. This migration gradually developed into a larger migration network facilitated through friends, relatives, and communities. Finally, rural-to-urban migration entered a phase guided by government regulation. Up to today, many if not the majority of peasant workers have been unprepared for the skills demanded by the urban labor market, and their general lack of education and training have seriously limited their upward mobility. Our qualitative findings inform us that strengthening and providing education opportunities and establishing vocational training and job-placement systems for migrant peasant workers are important initiatives to help them transition successfully into the urban labor market and to facilitate their moving up the occupational ladder.

Second, legalizing the status of migrant peasant workers is vital to achieving social equality. The rights of migrant peasant workers will not be protected if the household-registration system still stigmatizes peasant workers. Without reforming the household-registration system as a whole, social programs for migrant peasant workers will ultimately be efforts of sympathy and compassion rather than protections of their basic rights or contributions to improved social status. The protection of employment and other fundamental rights of peasant workers will be impossible if peasant workers are not allowed to live legally in the cities.

One of the limitations of this study is that the data were collected in 2005. Given the dramatic socioeconomic change in China in recent years, more recent data need to be analyzed to capture the most recent social trends. Still, the current analysis is important because the 2005 data have yet to be analyzed in the context of this paper's research questions, and this analysis establishes preliminary results for future studies. An additional limitation is that this study is based on a small sample $(n=109)$ of qualitative interviews. However, this approach provides insightful details about social mobility of migrant peasant workers in China and helps provide a framework for future analyses of larger, quantitative datasets.

In discussing the future direction of social mobility and urbanization in China, Xiaotong Fei, a famous sociologist in China, proposed in the 1980s a "small town" theory that advocates the establishment and development of small township enterprises so that peasants can obtain employment in their hometown and do not need to migrate to urban regions. This idea has been called "leave the land but not home." Since the birth of this theory, the reality is that the economic growth in the middle and large cities has been substantial, whereas the economic development has not begun for the small towns until recent years. Regional inequality and urban stratification are the objective realities of urbanization in China. The common decision of migrant peasant workers to return home provides an indication that urbanization in China may not be dependent upon only one path-investing in the large metropolitan cities-but may also need to undertake a broad range of development, including in small towns. Policies are needed to provide incentives to help individuals invest in small towns and provide would-be migrant peasant workers with options to integrate themselves into their home communities.

\section{References}

Bai, N., \& He, Y. (2003). "Returning or town?” In P. L. Li (Ed.), Migrant workers: Migrant workers in China's economic and social analysis (p. 27), Beijing: Social Sciences Academic Press.

Bai, N., \& Li, J. (2008). China's urbanization and rural labor migration. Chinese Journal of Population Science, 4, 2-10.

Bian, A. (2002), Chinese social stratification and social mobility, Annual Review of Sociology, 28, 91-116. doi:10.1146/annurev.soc.28.110601.140823

Cai, F., \& Wang, M. Y. (2002). How rapid is the economic growth of China? International Economic Review, 5, 49-52.

Cai, F. \& Wang, M. Y. (2010). Growth and structural changes in employment in transition China. Journal of Comparative Economics, 38, 71-81. doi:10.1016/j.jce.2009.10.006

Chan, K. W., \& Zhang, L. (1999). The Hukou system and rural-urban migration in China: Processes and changes. China Quarterly, 160, 818-855. doi:10.1017/S0305741000001351

Hassler, J., \& Rodriguez, J. V. (2000). Intelligence, social mobility, and growth, The American Economic Review, 4, 888. doi:10.1257/aer.90.4.888

Kerbo, H. R. (1991). Social stratification and inequality: Class conflict in historical and comparative perspective (second edition), New York: McGraw-Hill, Inc.

Lenski, G. E. (1984). Power and privilege: A theory of social stratification. Chapel Hill, NC: The University of North Carolina Press.

Levine, R. (Ed.). (2006). Social class and stratification: Classic statements and theoretical debates. New York, NY: Rowman \& Littlefield Publishers.

Li, P., \& Li, W. (2007). Migrant worker's economic status and social attitude in the transition of China. Sociological Studies, 3, 1-17.

Li, Q. (2004) Peasant workers and social stratification, Beijing: Social Sciences Academic Press.

Lin, K. (2009). China: The art of state and social policy remodeling. In P. Alcock and G. Craig (eds.), International social policy: Welfare regimes in the developed world (pp. 247-66), New York, NY: Palgrave MacMillan.

State Council Research Office. (2006). Chinese migrant workers research report. Beijing: State Council of China.

Watson, J. L. (2010). Class and social stratification in post-revolution China. London: Cambridge University Press.

Weber, M. (1964). The theory of social and economic organization. New York, NY: The Free Press.

Wu, X., \& Treiman, D. J. (2004). The household registration system and social stratification in China, 1955-1996. Demography, 41, 363-384. doi:10.1353/dem.2004.0010

Wu, X., \& Treiman, D. J. (2007). Inequality and equality under Chinese socialism: The Hukou system and intergenerational occupational mobility. American Journal of Sociology, 113, 415-445. doi:10.1086/518905

Zhao, A. (2003). The role of migrant networks in labor migrant: The case of China, Contemporary Economic Policy, 4, 500-511. 
doi:10.1093/cep/byg028

Zheng, G. (2006). Scientific development of a shared harmony: The livelihood of the people from the perspective of a harmonious society. Beijing: People's Press. 